\title{
Molecular characterization of Campylobacter spp. isolated from poultry faeces and carcasses in Poland
}

\author{
Kinga Wieczorek, Jacek Osek \\ Department of Hygiene of Food of Animal Origin, National Veterinary Research Institute, Pulawy, Poland
}

Received January 20, 2010

Accepted September 21, 2010

\begin{abstract}
Campylobacter infection is one of the most common enteric human diseases world-wide but the mechanism of Campylobacter pathogenicity has not been exactly explained yet. One of the main reasons is genotypic, hence phenotypic diversity of the bacterial isolates. The aim of the present study was to perform a molecular characterization of randomly selected $C$. jejuni and $C$. coli strains isolated from poultry faeces and carcasses in Poland. Several virulence gene markers were identified by polymerase chain reaction (PCR). Furthermore, genetic typing has also been used by the macrorestriction profiling with pulsed-field gel electrophoresis (PFGE). The results of the present study showed that all analyzed isolates of $C$. jejuni $(\mathrm{n}=24)$ and $C$. coli $(\mathrm{n}=$ 24) contained the $f a A$ and $c a d F$ sequences. On the other hand, the virB11 gene was present only in 6 of $48(12.5 \%)$ of the analyzed isolates, whereas most of the strains contained the $c d t$ genes. Other virulence gene iam linked to Campylobacter invasiveness was present in 34 of $48(72.9 \%)$ strains. The restriction analysis of the whole genome digested with SmaI produced three main clonal groups designed as I, II (with two subgroups IIa and IIb), and III obtained by the comparison of macrorestriction profiling patterns. The results showed a poor correlation between Campylobacter profiles generated by a clonal molecular technique and the presence of virulence markers. Therefore, PCR detection of Campylobacter virulence markers can be utilized as a simple and rapid tool to discriminate stains recovered from different sources, especially when used in conjunction with the PFGE profile analysis as a complex strategy. These kinds of analyses had not been previously carried out in Poland and these results may generate more knowledge regarding the genetic diversity and molecular relationship of Campylobacter.
\end{abstract}

Campylobacter, virulence markers, molecular analysis, PCR, PFGE

According to the recentEuropean Food Safety Authority(EFSA) report, the most frequently reported zoonotic disease in humans in the European Union in 2008 was Campylobacter infection, with incidences of 40.7 per 100,000 people (http://www.efsa.europa.eu). The infection with Campylobacter spp. (campylobacteriosis), especially with C. jejuni, and to a lesser extent with $C$. coli, is one of the leading causes of bacterial diarrhoea worldwide. During last years, laboratory confirmed incidence of campylobacteriosis in Poland. In 2008 , according to the EFSA report, there were 257 cases of the disease $(0.7 / 100,000$ population), however, it seems that the number of cases is still underestimated due to a lack of proper identification of the infectious agent. Poultry and its meat is considered to be the main vector of C. jejuni; transmission occurs either as a result of cross contamination due to improper handling of raw meat or consumption of undercooked food of animal (mainly poultry) origin.

The mechanism of Campylobacter pathogenicity has not been exactly explained yet. One of the main reasons is genotypic, hence phenotypic diversity of the bacterial species belong to the genus of Campylobacter. For the consumers' safety it is essential to characterize pathogenicity markers in strains that are identified in food. It was found that some $C$. jejuni strains are not pathogenic at all or induce mild symptoms in humans, whereas other isolates cause a serious illness (Rivera-Amill et al. 2001). It is still not clear which factors of Campylobacter are essential to the disease development. However, it is known that mechanisms of movement, chemotaxy, adhesion, transcytosis and host cell penetration as

Address for correspondence:

Jacek Osek

Department of Hygiene of Food of Animal Origin

National Veterinary Research Institute, Partyzantow 57

24-100 Pulawy, Poland
Phone: $+48-81-8893182$

Fax: $+48-81-8862595$

E-mail: josek@piwet.pulawy.pl

http://www.vfu.cz/acta-vet/actavet.htm 
well as toxin production are necessary to induce campylobacteriosis in humans (Snelling et al. 2005). Several putative or defined virulence markers of Campylobacter spp. have been described (Bang et al. 2003; Datta et al. 2003). One of the best characterized Campylobacter virulence markers is the flaA gene which determines the flagella formation, hence bacteria motility and enterocyte colonization (Nuijten et al. 2000). Molecular identification and differentiation of Campylobacter strains isolated from the same or different samples is very important in order to trace the sources of human infection. The methods used for genetic characterization differ in their taxonomic range, discriminatory power, reproducibility, easiness of interpretation, and standardization. Macrorestriction profiling (MRP) by pulsed-field gel electrophoresis (PFGE) has been proved to be useful for this purpose, and its discriminatory power can be enhanced by increasing the number of restriction enzymes used ( $\mathrm{On}$ et al. 1998). This method is currently a golden standard for the typing of Campylobacter spp. (Schouls et al. 2003).

The aim of the present study was to perform a molecular characterization of randomly selected $C$. jejuni and $C$. coli strains isolated from poultry faeces and carcasses in Poland. For this purpose, 7 virulence genes important in pathogenesis of campylobacteriosis were chosen and identified by the PCR method. These molecular markers participate in adhesion and colonization ( $f l a A, c a d F)$, invasion (virB11) and toxin production ( $c d t A, c d t B, c d t C)$. Moreover, the iam sequence connected with diarrhoeal form of the disease was also identified. Furthermore, molecular characterization of the investigated Campylobacter strains were further performed by macrorestriction profiling with PFGE.

\section{Materials and Methods}

Bacterial strains

The following positive and negative reference strains were included: $C$. jejuni ATCC 33291, C. coli ATCC 43478, Escherichia coli EDL 933, and Salmonella Typhimurium ATCC 14028.

All Campylobacter isolates were isolated from randomly chosen poultry faeces and carcasses in Poland during the period of September 2004 and July 2005. The samples were obtained from different regions of the country (administrative division - voivodship), including the following areas: northern (Pomorskie - P; WarminskoMazurskie - WM, Zachodniopomorskie - ZP voivodships), western (Dolnoslaskie - D, Lubuskie - L voivodships), southern (Opolskie - O, Slaskie - S voivodships), and eastern (Lubelskie - LU, Ludzkie - LD, Mazowieckie - M voivodships). All faecal samples were taken using swab method at farm level. From each farm one pooled sample (taken from at least ten fresh droppings) were examined. The carcass samples were collected at slaughterhouse at the end of processing level, from final products stored chilled $\left(<4{ }^{\circ} \mathrm{C}\right)$. For isolation of thermophilic Campylobacter spp., swabs inoculated with faeces or carcass samples were plated onto Campylobacter bloodfree selective medium such as mCCDA (Oxoid, UK) or Karmali Agar (Oxoid, UK) followed by incubation at $41.5^{\circ} \mathrm{C}$ for $40-48 \mathrm{~h}$ in microaerofilic conditions generated by the Campy Gen gas-generating kit (Oxoid, UK). Bacteria from individual colonies were stored (at $-80^{\circ} \mathrm{C}$ in nutrient broth, with glycerol added to $15 \%$ for genotypic analyses. Suspected bacterial colonies were tested by multiplex PCR (m-PCR) for the simultaneous detection of the $C$. jejuni and $C$. coli in a single reaction based on $16 S r R N A$ (specific for theromphilic Campylobacter), ceuE (specific for C. coli), and mapA genes (typical for C. jejuni), respectively (Wieczorek and Osek 2005). Total of 48 isolates ( 24 from faeces and 24 from poultry carcasses) were used in this study.

Detection of putative virulence genes by PCR

Campylobacter strains were grown at $41.5{ }^{\circ} \mathrm{C}$ in Karmali agar for $24 \mathrm{~h}$ under microaerophilic condition. A bacterial colony was suspended in $1 \mathrm{ml}$ of sterile water and centrifuged at $13000 \mathrm{~g}$ for $1 \mathrm{~min}$. Afterwards, DNA was extracted using the Genomic - Mini kit (A\&A Biotechnology, Poland) according to the manufacturer's instruction. The purity and concentration of the DNA preparations were estimated using spectrophotometry at 260 and $280 \mathrm{~nm}$.

Characteristics of all primers used in the study are shown in Table 1. The PCR primers were commercially synthesised (Symbiosis, Poland).

All PCRs were carried out in a thermal cycler (PTC-100, MJ Research, USA) under the following conditions: initial DNA denaturation at $94^{\circ} \mathrm{C}$ for 5 min followed by 30 cycles of $94^{\circ} \mathrm{C}$ for $1 \mathrm{~min}, 55^{\circ} \mathrm{C}$ for 1 min (with the exception for the $\mathrm{flaA}$ gene $-48^{\circ} \mathrm{C}$ for $1 \mathrm{~min}$ ) and $72{ }^{\circ} \mathrm{C}$ for $1 \mathrm{~min}$. The final extension step was run at $72{ }^{\circ} \mathrm{C}$ for $5 \mathrm{~min}$. The analysis of the amplified products was performed in $\%$ agarose (Sigma, USA) in Tris-Acetate-EDTA (TAE) buffer at $100 \mathrm{~V}$. The DNA bands were visualised by staining with ethidium bromide, analysed under UV light $(300 \mathrm{~nm})$ and photographed using the Gel Doc 2000 documentation system (Bio-Rad, USA). The size of the PCR amplicons was compared to the 100 bp DNA marker (Fermentas, EU). 
Table 1. Characteristics of PCR primers used in the study

\begin{tabular}{|c|c|c|c|c|c|}
\hline $\begin{array}{l}\text { Primer } \\
\text { name }\end{array}$ & Sequence $\left(5^{\prime} \rightarrow 3^{\prime}\right)$ & Target gene & $\begin{array}{c}\text { Size of PCR } \\
\text { amplicon (bp) }\end{array}$ & $\begin{array}{c}\text { Annealing } \\
\text { temperature }\left({ }^{\circ} \mathrm{C}\right)\end{array}$ & Reference \\
\hline$\overline{\text { CDTAF }}$ & CCTTGTGATGCAAGCAATC & $c d t A$ & 370 & $55^{\circ} \mathrm{C}$ & Bang et al. 2003 \\
\hline CDTAR & ACACTCCATTTGCTTTCTG & & & & \\
\hline CDTBF & CAGAAAGCAAATGGAGTGTT & $c d t B$ & 620 & $55^{\circ} \mathrm{C}$ & Datta et al. 2003 \\
\hline CDTBR & AGCTAAAAGCGGTGGAGTAT & & & & \\
\hline CDTCF & CGATGAGTTAAAACAAAAAGATA & $c d t C$ & 182 & $55^{\circ} \mathrm{C}$ & Datta et al. 2003 \\
\hline CDTCR & TTGGCATTATAGAAAATACAGTT & & & & \\
\hline F2B & TGGAGGGTAATTTAGATATG & $c a d F$ & 400 & $45^{\circ} \mathrm{C}$ & Konkel et al. 1999 \\
\hline R1B & CTAATACCTAAAGTTGAAAC & & & & \\
\hline IAMF & GCGCAAAATATTATCACCC & iam & 518 & $55^{\circ} \mathrm{C}$ & Korsak et al. 2005 \\
\hline IAMR & TTCACGACTACTATGCGG & & & & \\
\hline VirBF & GAACAGGAAGTGGAAAAACTAGC & virB11 & 708 & $55^{\circ} \mathrm{C}$ & Bang et al. 2003 \\
\hline VirBR & TTCCGCATTGGGCTATATG & & & & \\
\hline flaAF & GGATTTCGTATTAACACAAATGGTGC & $f l a A$ & 1700 & $48^{\circ} \mathrm{C}$ & Datta et al. 2003 \\
\hline flaAR & CTGTAGTAATCTTAAACATTTTG & & & & \\
\hline
\end{tabular}

Typing of Campylobacter strains by RFLP-PFGE

The DNA macrorestriction analysis was carried out using the One-Day (24-26 h) Standardized Laboratory Protocol for Molecular Subtyping of C. jejuni by pulsed field gel electrophoresis (PFGE) (Ribot et al. 2001). The plugs were digested with the restriction enzyme SmaI (Fermentas, EU) and the PFGE was run under the following conditions: pulse ramps from 5 to $40 \mathrm{~s}$ for $22 \mathrm{~h}$ at $4{ }^{\circ} \mathrm{C}$ at constant voltage of $6 \mathrm{~V}$ per $1 \mathrm{~cm}$. Dendrograms were constructed on the basis of the obtained DNA fragment patterns using the GelCompar II software (BioNumerics, Belgium) by the Unweighted Pair Group with Mathematic Average Method (UPGMA). Similarities between the profiles based on band position were derived by using the Dice's coefficient. The discriminatory power of the typing methods was calculated by using Simpson's index (D). All the isolates within a similarity between $90 \%$ and $100 \%$ were subject to belong to the same cluster (Hunter and Gaston 1988).

\section{Results}

Identification of virulence-associated genes

The results of the present study have shown that all analyzed isolates of $C$. jejuni and $C$. coli derived both from poultry faeces and carcasses possessed the flaA sequence. Another gene responsible for the colonization properties of Campylobacter spp. - cadF, was identified in $100 \%$ C. jejuni and C. coli isolates. On the other hand, the next virulence marker determining invasiveness of Campylobacter isolates - the virB11 gene, localized on pVir plasmid, was present only in 6 of $48(12.5 \%)$ of the analyzed bacterial strains (Table 2).

Further PCR identification of Campylobacter virulence markers revealed that most of the strains tested possessed the $c d t$ genes that are necessary for CDT toxin synthesis (Table 2). The majority of the isolates had the $c d t A$ and $c d t C$ markers $(70.8 \%$ strains of each gene variant). It should be noted that 17 out of $24 C$. jejuni isolates (70.8\%) possessed all three toxin subunit genes. On the other hand, among $C$. coli only 5 out of 24 strains $(20.8 \%)$ had all $c d t$ toxin genes together. Altogether, many more $C$. jejuni (from 87.5 to $95.8 \%$ ) than $C$. coli (45.8-70.8\%) isolates were identified to possess the $c d t$ genes (Table 2).

Identification of other virulence gene linked to Campylobacter invasiveness - iam has shown that this marker was present in 34 of $48(72.9 \%)$ of the investigated strains. It was found that this gene was much more predominant in C. coli (22 positive isolates, 91.7\%) than C. jejuni (13 positive isolates, $54.2 \%)$.

It was also shown that 34 out of 48 Campylobacter strains tested (70.8\%) possessed five or more of the 7 virulence-associated genes (Table 2). 


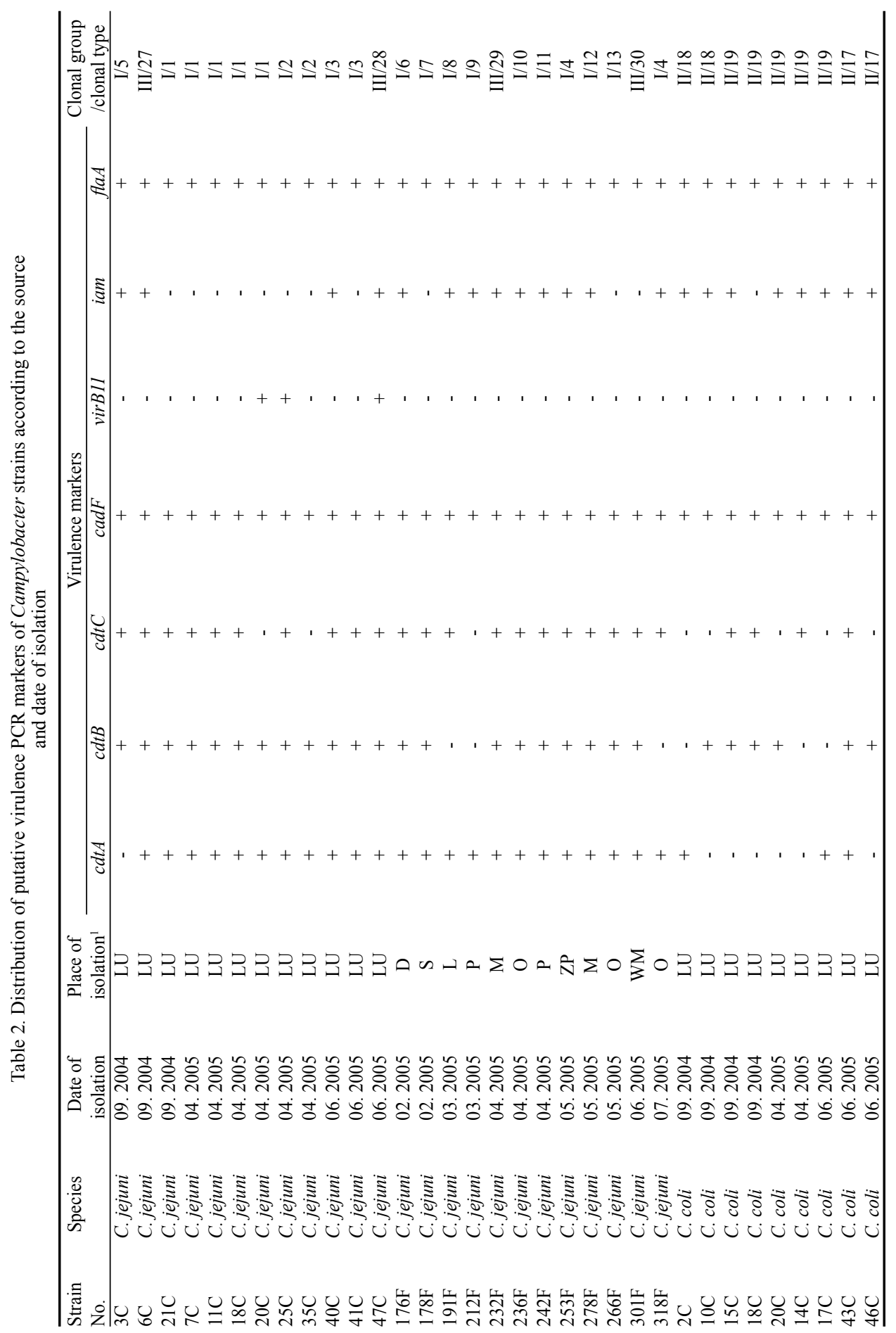




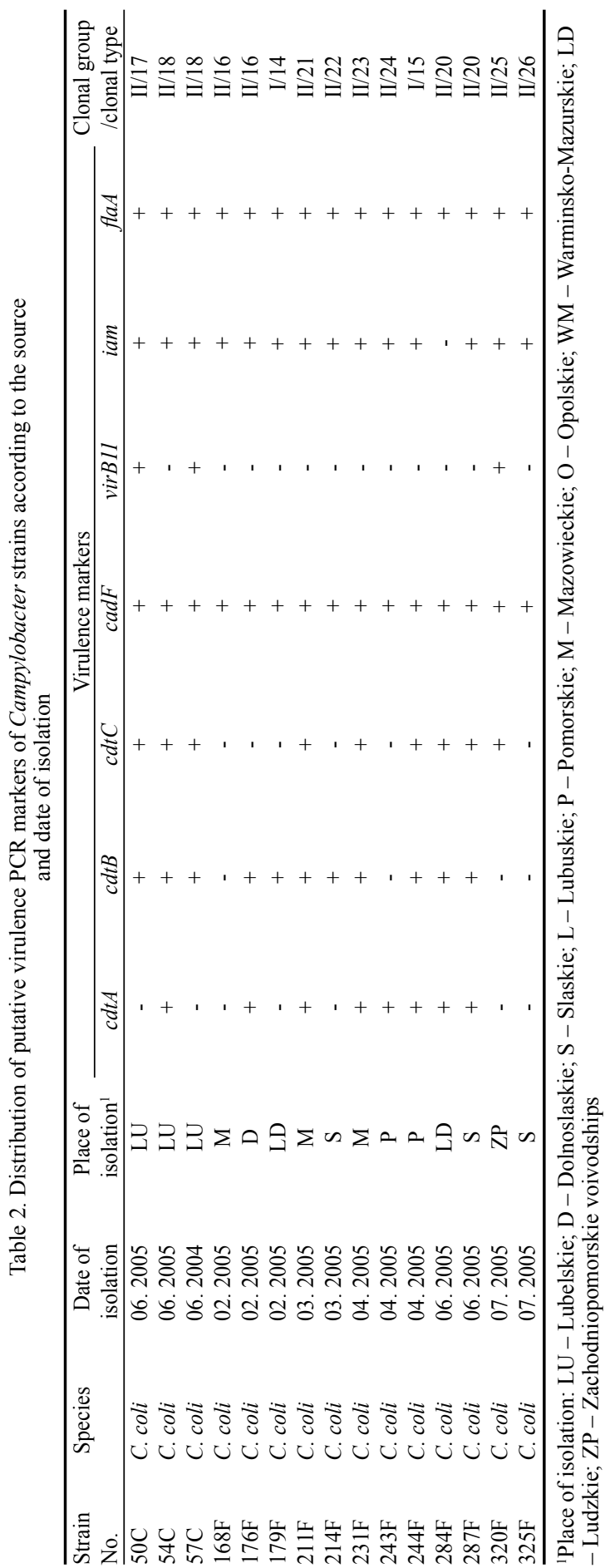

RFLP-PFGE typing

All MRPs were evaluated and assigned to arbitrarily defined profile groups (PGs). The results are summarized in Table 2 which also shows the information for each Campylobacter strain used in the study. The method was evaluated with respect to the discrimination index (D) and number of profiles obtained. All poultry faeces $(\mathrm{n}=$ $24)$ and carcass $(n=24)$ isolates were subjected to MRP using the restriction enzyme SmaI.

The mean differentiation index determined was 0.97. However, the PFGE D index was higher for the faeces strains $(0.98)$ than for the carcass isolates $(0.89)$.

In the dendrogram, pulsotypes were delineated with a $90 \%$ similarity of the cut-off level (Fig. 1). Thirty Campylobacter isolates displayed unique pulsotypes and six pulsotypes were shared by two or more isolates (Fig. 1). Two pulsotypes comprised 5 and another two pulsotypes contain 3 and 4 isolates, respectively. Three main clonal groups designed as I, II (with two subgroups - IIa and IIb), and III were formed by the comparison of MRP typing patterns (Fig. 1).

Clonal group I had 20 isolates belonging to $C$. jejuni whereas the 2 remaining isolates were identified as $C$. coli. This group comprised 15 unique SmaI pulsotypes, of which 2 clusters had 2 and 1 had 5 identical isolates.

Clonal group II consisted of 22 C. coli isolates. Restriction with SmaI split up them into two subgroups with 18 (subgroup IIa) and 4 (subgroup IIb) bacterial strains. Fourteen of the 18 isolates in the subgroup IIb were indistinguishable from each other after digestion with SmaI. 
$\begin{array}{llllllllll}10 & 20 & 30 & 40 & 50 & 60 & 70 & 80 & 90 & 100\end{array}$

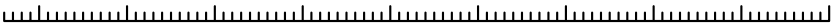

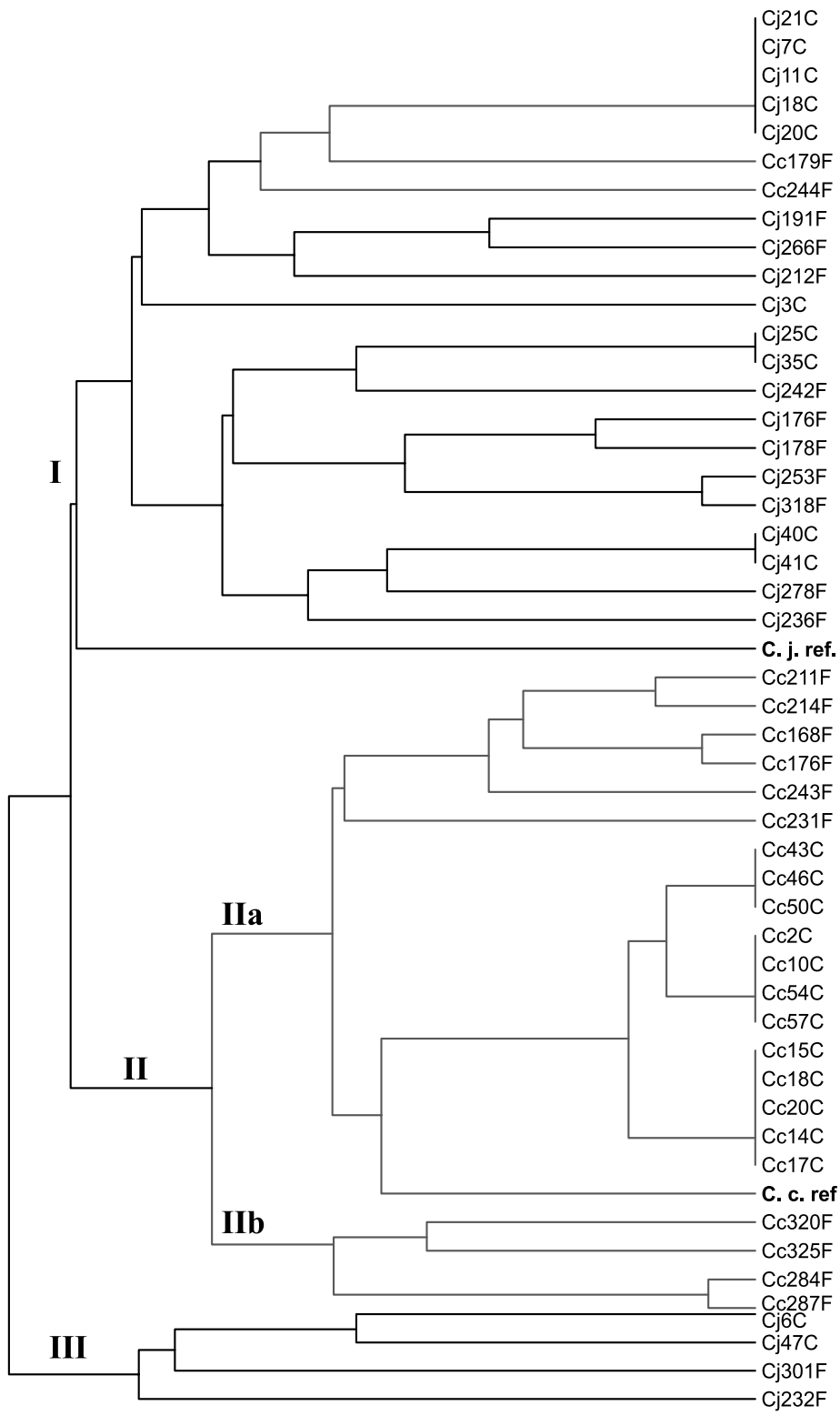

Fig. 1. Dendrogram based on RFLP-PFGE fragments patterns of 48 C. jejuni and C. coli isolates from poultry faeces and carcasses. The scale measures similarity values. Carcasse Campylobacter isolates marked with $\mathrm{C}$ letter and faeces Campylobacter isolates marked with F letter. Two reference $C$. coli ATCC43478 and $C$. jejuni ATCC 33291 strains are included and marked as C. c. ref. and C. j. ref., respectively.

The group III covered 4 C. jejuni isolates ( 2 carcass and 2 faeces origin) that displayed unique pulsotype (Fig. 1). 


\section{Discussion}

Identification of putative virulence markers

One of the best characterized Campylobacter pathogenic marker is the flaA gene which determines flagella formation, hence bacteria motility and enterocyte colonization (Nuijten et al. 2000). Results of the present study showed that all analyzed isolates of $C$. jejuni and C. coli derived both from carcass and poultry faeces possessed the flaA sequence. Bang et al. (2003) examined the presence of this factor in $C$. jejuni and $C$. coli derived from swine and cattle (together 40 isolates), and obtained the same results, i.e. 100\% positive Campylobacter strains. Similar results were found by Datta et al. (2003) who determined the flaA factor in the group of $111 C$. jejuni derived from human clinical specimens, poultry carcass, faeces, and cattle. All these results may suggest that the flaA gene product is necessary for bacterial colonization of animal alimentary tract and determines the stability of bacteria on the surface of contaminated poultry carcass. However, other virulence markers, e.g. $c a d F$ gene product may also participate in the colonization and adherence process. The cadF gene is highly conservative among $C$. jejuni and $C$. coli which may also suggest its crucial role in campylobacteriosis development (Monteville et al. 2003). As detected in the present study, the cadF gene was presented in $100 \%$ of the examined C. jejuni and C. coli isolated both from poultry carcass and faeces. Other authors also identified this virulence marker in all or almost all isolates tested that were derived from poultry carcass and faeces and from human clinical specimens (Bang et al. 2003; Datta et al. 2003; Rozynek et al. 2005).

The next virulence factor examined in the present study was one of the markers determining the invasiveness of Campylobacter isolates - the virB11 gene, localized on in pVir plasmid. The gene was present only in 6 from $48(12.5 \%)$ analyzed bacterial isolates, equally in $C$. jejuni and $C$. coli strains (3 positive strains of each species). The low percentage of such virB11-positive Campylobacter isolates was also described by other authors (Bang et al. 2003; Datta et al. 20003; Louwen et al. 2006). However, the role of this gene marker in pathogenesis of campylobacteriosis in humans is still not clear. Tracz et al. (2005) suggested that products of the pVir plasmid genes may play a major role in the serious symptoms of the illness caused by $C$. jejuni. On the other hand, Louwen et al. (2006) claimed that this plasmid does not play any role in the induction of bloody diarrhoea in infected humans.

Toxins produced by Campylobacter might be another factor that potentially plays a role in the disease development. CDT toxin composed of three subunits: $\mathrm{CdtA}, \mathrm{CdtB}$, and $\mathrm{CdtC}$ is one of the best described toxin molecules produced by $C$. coli and C. jejuni isolates (Martinez et al. 2006). All the above mentioned subunits are necessary to induce a cytotoxic effect in vitro. In our present study, three $c d t$ genes were examined. The majority of the isolates tested possessed the $c d t B$ gene (79.2\%). Several Campylobacter isolates had also the $\mathrm{c} d t C$ and $c d t A$ markers (both $70.8 \%$ of isolates). Furthermore, 17 out of $24 C$. jejuni isolates $(70.8 \%)$ possessed all three toxin gene subunits. On the other hand, only 5 out of 24 C. coli $(20.8 \%)$ isolates harbored all $c d t$ gene markers. When the source of the isolates was included, a higher percentage of $C$. jejuni $(87.5-95.8 \%)$ than $C$. coli $(45.8-70.8 \%)$ strains were positive for all $c d t$ genes. The percentage of toxin-positive Campylobacter examined by other authors was from $90 \%$ to $100 \%$ (Bang et al. 2001, 2003; Datta et al. 2003; Martinez et al. 2006). However, little information concerning the prevalence of the $c d t A, c d t B$ and $c d t C$ genes had been published in Poland. Rozynek et al. (2005) identified these virulence markers in $77.5 \%, 93.8 \%, 77.5 \%$ of isolates derived from children with diarrhoea $(\mathrm{n}=80)$ as well as in $94.6 \%$ and $98.9 \%$ of the isolates derived from poultry carcasses $(n=92)$.

The other putative virulence gene, i.e. iam connected with diarrhoea in patients infected with Campylobacter, was also detected during the present investigation. The iam PCR 
product was found in 35 of $48(72.9 \%)$ strains tested. The similar percentage of the positive isolates was identified by Korsak et al. (2005) who analyzed Campylobacter strains derived from chicken carcasses in Poland.

\section{MRP by PFGE results}

The discriminatory power of MRP obtained by the by PFGE method described in our study was rather high. Similar results have also been reported by other studies (Rivoal et al. 2005). The pulsotypes obtained after digestion with SmaI revealed that $C$. jejuni and C. coli are genetically diverse. Three main clusters comprising 30 out of the 48 SmaIdigested isolates were obtained. As shown in the present study, identical genotypes were commonly present in isolates from the same source and time of the isolation, e.g. 43C, $46 \mathrm{C}$, and $50 \mathrm{C}$ that were recovered from poultry carcasses from the same region of Poland as well as on the same day. On the other hand, strains $3 \mathrm{C}$ and $6 \mathrm{C}$ were isolated from the same country region (Lubelskie voivodship) and at the same time but belong to different clonal groups - I and III, respectively. Previous studies have also shown that several Campylobacter genotypes can coexist among individual chickens (Schouls et al. 2003) and that individual farms can be contaminated with multiple clones (Stanley and Jones 2003; Rivoal et al. 2005).

As shown in the present study, $C$. jejuni and $C$. coli broiler isolates were fairly evenly distributed between the clonal clusters. Groups I and III comprised all $C$. jejuni isolates (plus 2 C. coli strains $-179 \mathrm{~F}$ and $244 \mathrm{~F}$ ), whereas group II covered only C. coli. These results are in agreement with several other studies that have also demonstrated the ability of the PFGE method to discriminate between and within Campylobacter species (Rivoal et al. 2005). Furthermore, majority of the isolates of the same species, isolated from faeces and carcasses, were clustered together. Less diversity was found among Campylobacter strains derived from carcasses, which displayed eight different genotypes compared to 22 different PFGE profiles of the isolates of faecal origin (Fig. 1).

\section{Relationship between present virulence genes and PFGE profile}

The results obtained showed a poor correlation between profiles generated by a clonal molecular technique and the presence of virulence markers. However, this kind of comparative analysis sometimes allowed differentiating strains with identical patterns. For example, isolates W25 and W35 shared the same PFGE profiles but were differentiated by the presence of the different putative virulence genes because only strain W25 possessed the $c d t C$ and virB 11 markers. The opposite observations were made when the strains were analyzed with respect to the presence of virulence markers. Campylobacter isolates with different PFGE profiles, such as $242 \mathrm{D}$ and $253 \mathrm{C}$, were found to possess the same virulence genes. On the other hand, some strains e.g. C. jejuni $21 \mathrm{C}, 7 \mathrm{C}, 11 \mathrm{C}, 18 \mathrm{C}$ could not be distinguished even if both methods (PFGE and virulence gene determination) were used.

Our data show that most $C$. jejuni and $C$. coli strains isolated from poultry faeces and carcasses carrying genes linked to severe forms of human campylobacteriosis. Molecular profiles of Campylobacter spp. can contribute to microbial risk assessment by helping to assess the relative risks of cross-contamination of food of animal origin. The results also showed that MRP based on PFGE is a useful method for the determination of Campylobacter identification and eradication of the major reservoirs of the common bacterial clones. Furthermore, PCR detection of Campylobacter virulence markers can be utilized as a simple and rapid tool to discriminate stains recovered from different sources, especially when used in conjunction with the PFGE profile analysis as a complex strategy. These data, when considered with studies demonstrating that Campylobacter strains are significantly different in their ability to produce various toxins, may indicate that not all strains occurring in animals may be pathogenic for humans. Thus, the ability to identify 
certain clones of known pathogenicity may be more relevant to public health protection than simply detecting the presence of Campylobacter spp.

\section{References}

Bang DD, Nielsen EM, Scheutz F, Pedersen K, Handberg K, Madsen M 2003: PCR detection of seven virulence and toxin genes of Campylobacter jejuni and Campylobacter coli isolates from Danish pigs and cattle and cytolethal distending toxin production of the isolates. J Appl Microbiol 94: 1003-1014

Bang DD, Scheutz F, Ahrens P, Pedersen K, Blom J, Madsen M 2001: Prevalence of cytolethal distending toxin (cdt) genes and CDT production in Campylobacter spp. isolated from Danish broilers. J Med Microbiol 50: $1087-1094$

Datta S, Niwa H, Itoh K 2003: Prevalence of 11 pathogenic genes of Campylobacter jejuni by PCR in strains isolated from humans, poultry meat and broiler and bovine faeces. J Med Microbiol 52: 345-348

European Food Safety Authority http://www.efsa.europa.eu

Hunter PR, Gaston MA 1988: Numerical index of the discriminatory ability of typing systems: an application of Simpson's index of diversity. J Clin Microbiol 26: 2465-2466

Konkel ME, Gray SA, Kim BJ, Garvis SG, Yoon J 1999: Identification of the enteropathogens Campylobacter jejuni and Campylobacter coli based on the cadF virulence gene and its product. J Clin Microbiol 38: $510-517$

Korsak D, Dzierzanowska-Fangrat K, Popowski J, Rozynek E 2005: Occurrence of virulence markers iam in Campylobacter jejuni i Campylobacter coli strains isolated from chicken carcasses. Roczn PZH 55: $307-312$

Louwen RP, van Belkum A, Wagenaar JA, Doorduyn Y, Achterberg R, Endtz H.P 2006: Lack of association between the presence of the pVir plasmid and bloody diarrhea in Campylobacter jejuni enteritis. J Clin Microbiol 44: 1867-1868

Martinez I, Mateo E, Churruca E, Girbau C, Alonso R, Fernandez-Astorga A 2006: Detection of $c d t A, c d t B$, and $c d t C$ genes in Campylobacter jejuni by multiplex PCR. Int J Med Microbiol 296: 45-48

Monteville MR, Yoon JE, Konkel ME 2003: Maximal adherence and invasion of INT 407 cells by Campylobacter jejuni requires the $\mathrm{CadF}$ outer-membrane protein and microfilament reorganization. Microbiology 149: $153-165$

Nuijten PJ, van den Berg AJ, Formentini I, van der Zeijst BA, Jacobs AA 2000: DNA rearrangements in the flagellin locus of an flaA mutant of Campylobacter jejuni during colonization of chicken ceca. Infect Immun 68: $7137-7140$

On SL, Nielsen EM, Engberg J, Madsen M 1998: Validity of SmaI-defined genotypes of Campylobacter jejuni examined by $S a c$ II, KpnI, and BamHI polymorphisms: evidence of identical clones infecting humans, poultry, and cattle. Epidemiol Infect 120: 231-237

Ribot EM, Fitzgerald C, Kubota K, Swaminathan B, Barrett TJ 2001: Rapid pulsed-field gel electrophoresis protocol for subtyping of Campylobacter jejuni. J Clin Microbiol 39: 1889-1894

Rivera-Amill V, Kim BJ, Seshu J, Konkel ME 2001: Secretion of the virulence-associated Campylobacter invasion antigens from Campylobacter jejuni requires a stimulatory signal. J Infect Dis 183: 1607-1616

Rivoal K, Ragimbeau C, Salvat G, Colin P, Ermel G 2005: Genomic diversity of Campylobacter coli and Campylobacter jejuni isolates recovered from free-range broiler farms and comparison with isolates of various origins. Appl Environ Microbiol 71: 6216-6227

Rozynek E, Dzierzanowska-Fangrat K, Jozwiak P, Popowski J, Korsak D, Dzierzanowska D 2005: Prevalence of potential virulence markers in Polish Campylobacter jejuni and Campylobacter coli isolates obtained from hospitalized children and from chicken carcasses. J Med Microbiol 54: 615-619

Schouls L M, Reulen S, Duim B, Wagenaar J A, Willems R J, Dingle K E, Colles F M, Van Embden J D 2003: Comparative genotyping of Campylobacter jejuni by amplified fragment length polymorphism, multilocus sequence typing, and short repeat sequencing: strain diversity, host range, and recombination. J Clin Microbiol 41: $15-26$

Snelling WJ, Matsuda M, Moore JE, Dooley JS 2005: Campylobacter jejuni. Lett Appl Microbiol 37: 297-302

Stanley K, Jones K 2003: Cattle and sheep farms as reservoirs of Campylobacter. J Appl Microbiol 94: $104 S-113 S$

Tracz DM, Keelan M, Ahmed-Bentley J, Gibreel A, Kowalewska-Grochowska K, Taylor DE 2005: pVir and bloody diarrhea in Campylobacter jejuni enteritis. Emerg Infect Dis 11: 838-843

Wieczorek K, Osek J 2005: Multiplex PCR assays for simultaneous identification of Campylobacter jejuni and Campylobacter coli. Vet Med 61: 797-799 